\title{
Three Cycles: \\ Housing, Credit, and Real Activity
}

\author{
Deniz Igan, Alain Kabundi, \\ Francisco Nadal De Simone, \\ Marcelo Pinheiro, and Natalia Tamirisa
}




\title{
IMF Working Paper
}

\author{
Research Department
}

\author{
Three Cycles: Housing, Credit, and Real Activity \\ Prepared by Deniz Igan, Alain Kabundi, Francisco Nadal De Simone, \\ Marcelo Pinheiro, and Natalia Tamirisa ${ }^{\dagger}$ \\ Authorized for distribution by Stijn Claessens
}

October 2009

\begin{abstract}
This Working Paper should not be reported as representing the views of the IMF. The views expressed in this Working Paper are those of the author(s) and do not necessarily represent those of the IMF or IMF policy. Working Papers describe research in progress by the author(s) and are published to elicit comments and to further debate.

We examine the characteristics and comovement of cycles in house prices, credit, real activity and interest rates in advanced economies during the past 25 years, using a dynamic generalized factor model. House price cycles generally lead credit and business cycles over the long term, while in the short to medium term the relationship varies across countries. Interest rates tend to lag other cycles at all time horizons. While global factors are important, the U.S. business cycle, house price cycle and interest rate cycle generally lead the respective cycles in other countries over all time horizons, while the U.S. credit cycle leads mainly over the long term.
\end{abstract}

JEL Classification Numbers: E32, E44, F40

Keywords: $\quad$ Macro-financial linkages, house prices, credit, business cycle

Authors’ E-Mail Addresses: $\quad$ digan@imf.org, akabundi@uj.ac.za, francisco.nadaldesimone@bcl.lu, mpinheiro@,cornerstone.com, ntamirisa@,imf.org

\footnotetext{
$\dagger$ The authors thank Tam Bayoumi, Stijn Claessens, James Hamilton, Ayhan Kose, Gianni De Nicolò, an anonymous referee, and participants in the WEAI 8th Pacific Rim Conference and the IMF Research Department's seminar for helpful comments. We are also grateful to David Velazquez-Romero, Angela Espiritu, and Gavin Asdorian for excellent research assistance. Francisco Nadal De Simone is with the Central Bank of Luxembourg. Marcelo Pinheiro is an associate at Cornerstone Research, Washington, D.C. The material discussed herein may not reflect the opinions of the Central Bank of Luxembourg or of Cornerstone Research.
} 


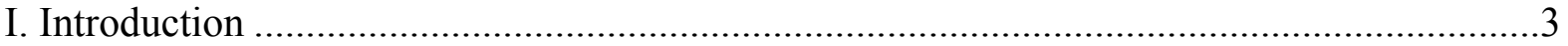

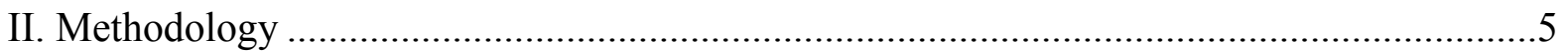

A. Common versus Idiosyncratic Components ....................................................

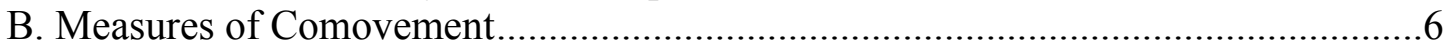

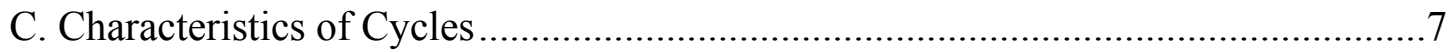

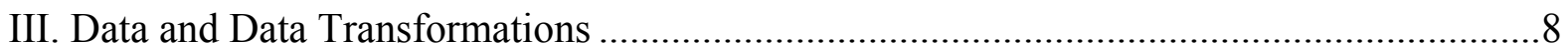

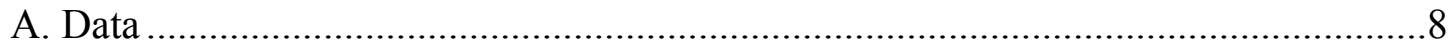

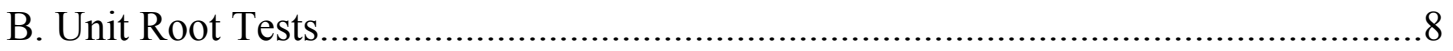

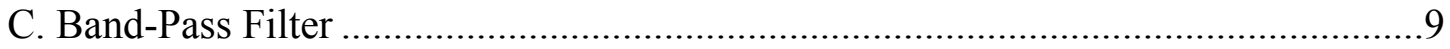

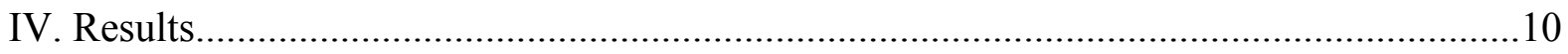

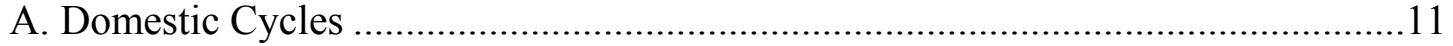

B. International Comovement of Cycles.......................................................... 13

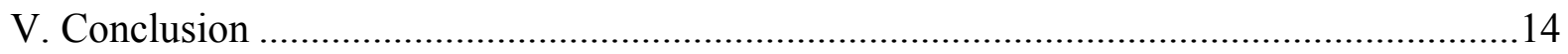

Figures:

1. $\quad$ Filtered versus Differenced Series ........................................ 16

2. Total Cyclical Movements of Real GDP, Credit and House Prices ............... 17

3. Total Cyclical Movements versus Common Components in

Selected Countries Real GDP ......................................... 19

4. Common Components for Selected Countries............................ 20

Tables:

1. Unit Root Tests .................................................... 21

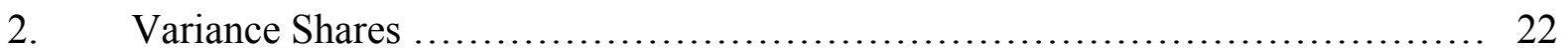

3. Cycle Characteristics .............................................. 23

4. Characteristics of Mortgagee Markets.................................... 24

5. Correlation Coefficients for Total Cyclical Components ........................ 24

6. Leads and Lags between Cycles within Countries............................. 25

7. Evolution of Cyclical Movements Driven by Common Components.............. 26

8. Lead-Lag Relations between the United States and Other Countries.............. 27

Appendix: Data Coverage and Sources.........................................28

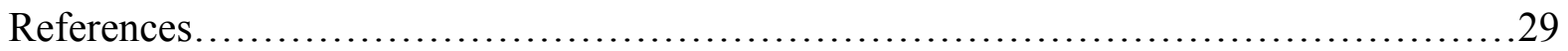




\section{INTRODUCTION}

This paper compiles and discusses stylized facts on the characteristics and comovement of cycles in house prices, bank credit, real activity and interest rates in advanced economies during the past 25 years. The focus is on two questions:

1. How closely has the cyclical behavior of house prices, bank credit and real economic activity been synchronized over different time horizons within countries? Are these cyclical patterns consistent with modern financial accelerator theories? How do they relate to interest rate cycles?

2. How closely has the cyclical behavior of house prices, bank credit and real economic activity been synchronized across countries? Is there evidence of some countries' cycles leading other countries' cycles?

On the first question, the business cycle literature points to a high degree of comovement in house prices, bank credit and real activity (for example, Stock and Watson, 1999). Bank credit and house prices typically rise during economic upswings, as firms and consumers demand more credit to expand investment and consumption; and during downturns these trends reverse. The financial accelerator theory suggests that financial cycles are likely to have a larger amplitude than real activity cycles and that the financial accelerator effects tend to amplify real economic cycles owing to the procyclicality of bank lending. Such procyclicality arises because changes in asset prices affect external finance premium (Bernanke and Gertler, 1989), the value of collateral (Kiyotaki and Moore, 1997) ${ }^{1}$ and/or bank leverage (Adrian and Shin, 2008; Berger and Bouwman, 2008). ${ }^{2}$

One would also expect to find a high degree of synchronization between the three cycles in question and the interest rate cycles, with interest rates being contemporaneous with other cycles or lagging them (to the extent that house prices reflect agents' interest rate expectations). Output, and to a lesser extent house prices and credit, tend to respond to interest rate shocks (Bernanke and Gertler, 1995; Mishkin, 2007; Assenmacher-Wesche and Gerlach, 2009). ${ }^{3}$ However, central banks in advanced economies have not targeted house

\footnotetext{
${ }^{1}$ Note that the link between credit and house prices works in both directions: the ease in credit constraints increases demand for housing and pushes house prices up, while rising house prices and collateral values improve the perceived creditworthiness of borrowers and enable them to borrow more.

${ }^{2}$ The increased liquidity of housing wealth owing to such regulatory factors as the availability of home equity loans or reversed mortgages have ambiguous effects on the relation between house prices and real activity: they can make consumption less dependent on current income, thereby stabilizing real activity cycles, but more dependent on asset prices, amplifying business cycle effects (Feldstein, 2007; Leamer, 2007).

${ }^{3}$ Changes in interest rates can affect the housing market through various channels, including through the effect on the user cost of capital, expectations of future house price movements and housing supply, as well as wealth effects from house prices, balance sheet and credit channel effects on consumer spending and housing demand. The strength of these transmission channels is likely to depend on institutional and regulatory factors pertaining to the housing market.
} 
prices and credit, ${ }^{4}$ as monetary policy is considered to be an ineffective tool for achieving these objectives (Bernanke, Gertler and Gilchrist, 1999).

On the second question, there is largely a consensus in the literature that globalization and financial innovation have strengthened the degree of synchronization in macroeconomic and financial cycles in advanced countries (Kose, Prasad, and Terrones, 2003; Imbs, 2004; Kose, Otrok, and Whiteman, 2008). However, the United States has continued to play a leading role in global business cycle fluctuations (Kabundi and Nadal De Simone, 2007a and b). ${ }^{5}$ International comovement in house prices has often been linked to comovement in interest rates. Global liquidity has also been identified as an important factor contributing to increases in house prices in a broad range of countries (Belke and Orth, 2008).

We take a descriptive approach to answer the above questions. Using a dynamic generalized factor model (Giannone, Reichlin, and Sala, 2002; Forni and others, 2005; Eickmeier, 2007), we extract common components from a broad range of economic and financial indicators for 20 advanced economies for the period from 1981:Q1 to 2006:Q4. The data cover real activity indicators, credit aggregates, stock and house prices, short- and longterm interest rates, and household wealth. We measure the degree of comovement between the cycles using dynamic correlations (Croux, Forni, and Reichlin, 2001), coherence and phase-angle statistics and use statistical tests to identify leads and lags between the cycles. ${ }^{6}$

The findings of our paper can be summarized as follows:

1. Over the short to medium term, the lead-lag relationships between house price, credit and real activity cycles tend to vary across countries, suggesting that the financial accelerator mechanisms differ. ${ }^{7}$ Over the long term, house prices lead credit and real activity in all countries. Long-term movements in house prices may be driven by slow changing fundamentals (for example, demographics and zoning regulations), which in turn drive demand for credit and real activity. Interest rates lag house prices and

\footnotetext{
${ }^{4}$ Most central banks considered developments in monetary and credit aggregates and asset prices when making interest rate decisions, and the European Central Bank and the Bank of Japan included credit variables as separate "pillars" of monetary policy. Some authors argued for a proactive role of central banks in "leaning against the wind" of changes in credit growth and asset price increases, particularly forcefully raising interest rates to prevent bubbles from reaching unsustainable proportions (Borio and Lowe, 2002; Borio, 2006).

${ }^{5}$ There is some conflicting evidence of lower synchronization, possibly reflecting increased economic specialization (Kose and Yi, 2006; Kose and others, 2003).

${ }^{6}$ Our paper relates to the recent papers by Goodhart and Hofmann (2008) and Otrok and Terrones (2007), which also examine multi-dimensional linkages among macroeconomic and financial variables. Goodhart and Hofmann (2008) use a fixed-effects panel vector autoregression, while Otrok and Terrones (2007) use factoraugmented VAR. In contrast to these papers, we use a simple descriptive approach. We focus on documenting patterns of cyclical fluctuations and international comovement of cycles.

7 The short to medium term is defined here as 6 to 16 quarters, in line with the National Bureau of Economic Research (NBER)'s definition of "minor" cycle. The long term is defined here as 16 to 32 quarters, or the NBER's “major” cycle.
} 
credit or are contemporaneous over the short to medium term. Over the long term, interest rates tend to lag real output and house prices, and, to a lesser extent, credit.

2. Country cycles in house prices, credit and real activity are largely driven by common factors, and the role of such factors appears to have increased over time, possibly owing to growing financial integration. The U.S. cycles in real activity, house prices and interest rates tend to lead other countries' respective cycles over all time horizons, while the U.S. credit cycle leads only in the long run. The finding points to significant spillovers from the United States to the rest of the world, and underlines the need to take into account not only domestic but also global trends in house prices and credit when analyzing the economic outlook.

The rest of the paper is organized as follows. Section II discusses methodology. Section III reviews data and data transformations. Section IV presents results. Section V concludes.

\section{Methodology}

\section{A. Common versus Idiosyncratic Components}

To disentangle the common from the idiosyncratic components of the variables of interest, we use a large-dimensional approximate generalized dynamic factor model (GDFM). The model is closely related to the traditional factor models of Sargent and Sims (1977) and Geweke (1977), except that it allows for the possibility of serial correlation and weakly cross-sectional correlation of idiosyncratic components, as in Chamberlain (1983) and Chamberlain and Rothschild (1983). ${ }^{8}$

The approximate dynamic factor model analysis focuses on identifying a common component using a large number of series. A vector of time series $Y_{t}=\left(y_{1 t}, y_{2 t}, \ldots, y_{N t}\right)^{\prime}$ can be represented as the sum of two latent components, a common component $X_{t}=\left(x_{1 t}, x_{2 t}, \ldots, x_{N t}\right)^{\prime}$, which is driven by a small number of shocks that are common to the entire panel, and an idiosyncratic component $\mathrm{E}_{t}=\left(\varepsilon_{1 t}, \varepsilon_{2 t}, \ldots, \varepsilon_{N t}\right)^{\prime}$, which is specific to a particular series and orthogonal to the common component. Hence,

$$
\begin{aligned}
& Y_{t}=X_{t}+\mathrm{E}_{t} \\
& Y_{t}=C F_{t}+\mathrm{E}_{t}
\end{aligned}
$$

where $F_{t}=\left(f_{1 t}, f_{2 t}, \ldots, f_{r t}\right)^{\prime}$ is a vector of $r$ common factors and $C=\left(c_{1}^{\prime}, c^{\prime}{ }_{2}, \ldots, c_{N}^{\prime}\right)^{\prime}$ is an $N \times r$ matrix of factor loadings, with $r<<N$. The common component $X_{t}$, which is a linear

\footnotetext{
${ }^{8}$ Similar models have recently been used by Giannone, Reichlin, and Sala (2002), Forni and others (2005), Eickmeier (2007), and Kabundi and Nadal De Simone (2007).
} 
combination of common factors, is driven by a limited number of common shocks, which are the same for all variables. Nevertheless, the effects of the common shocks differ from one variable to another and from one country to another due to different factor loadings. In this framework and in contrast to standard common component analysis, the idiosyncratic component is driven by idiosyncratic shocks, which are specific to each variable and country. The dynamic factor model used here differs from the static factor model in that it treats lagged or dynamic factors $F_{t}$ as additional static factors. Thus, common factors include both lagged and contemporaneous factors.

Identification of the common components requires the number of series to be much larger than the number of observations. Stock and Watson (1998) demonstrate that the idiosyncratic component, which is weakly correlated by construction, vanishes through application of the law of large numbers (as $T, N \rightarrow \infty$ ); and therefore, the common component can be easily estimated in a consistent manner by using standard principal component analysis. The first $r$ eigenvalues and eigenvectors are calculated from the variance-covariance matrix, $\operatorname{cov}\left(Y_{t}\right)$.

$$
X_{t}=V V^{\prime} Y_{t}
$$

and since the factor loadings $C=V$, Equation (1) becomes

$$
F_{t}=V^{\prime} Y_{t}
$$

From (1), the idiosyncratic component is

$$
\mathrm{E}_{t}=Y_{t}-X_{t}
$$

From all the more or less formal criteria to determine the number of static factors $r$, Bai and $\mathrm{Ng}$ (2002) information criteria is selected for use in this study. As in Forni and others (2005), $F_{t}$ is approximated by an autoregressive representation of order 1:

$$
F_{t}=B F_{t-1}+u_{t}
$$

where $B$ is an $r \times r$ matrix and $u_{t}$ an $r \times t$ vector of residuals. Equation (5) is the reduced form model of the common component in equation (1).

\section{B. Measures of Comovement}

To evaluate the structure of the comovements among the series of interest, including leads and lags, we use the measures of dynamic correlation, coherence, and phase angle. The dynamic correlation between two stochastic processes is the correlation coefficient between the real part of their spectral decomposition (see Croux, Forni and Reichlin, 2001, and Fuller, 1976, for technical details). The dynamic correlation varies between -1 and +1 . Formally, 


$$
\rho_{y 1 y 2}=\frac{C_{y 1 y 2}(\lambda)}{\sqrt{S_{y 1}(\lambda) S_{y 2}(\lambda)}}
$$

where $C_{y 1 y 2}(\lambda)$ is the cospectrum between $y_{1}$ and $y_{2}$ processes at frequency $\lambda$ and $S_{y 1}$ and $S_{y 2}$ are the spectral density functions of the processes at frequency $\lambda$ defined over $-\pi$ and $\pi$.

Coherence is intrinsically related to the dynamic correlation and is given by

$$
K_{y 1 y 2}(\lambda)=\frac{\left|S_{y 1 y 2}(\lambda)\right|^{2}}{S_{y 1}(\lambda) S_{y 2}(\lambda)}
$$

The coherence is symmetric and a real number between 0 and 1 . It does not measure correlation at different frequencies. It disregards the phase angle shifts between the variables, and can thus be interpreted as the $A^{2}$ from the regression of $y_{1}$ on $y_{2}$.

The phase angle between processes $y_{1}$ and $y_{2}$ helps identify the lead-lag relationship and is given by

$$
\varphi_{y 1 y 2}(\lambda)=\tan ^{-1}\left(q_{y 1 y 2} \mid C_{y 1 y 2}\right)
$$

where $q_{q_{1} x_{2} 2}$ is the quadrature spectrum. Only when $K_{F_{1}: 2}(\lambda) \neq 0$, the phase angle converges in distribution to a normal random variable. When the coherence is significant, it is possible to construct confidence intervals for the lead and lag relations between the two processes.

\section{Characteristics of Cycles}

To date the cycles, we use the classical definition of the business cycle based on the turning points in the level of aggregate economic activity (Burns and Mitchell, 1946). To locate turning points in the cycles, we follow the algorithm originally suggested by Bry and Boschan (1971) and developed by Harding and Pagan (2002), which operationalizes the original approach in Burns and Mitchell (1946). The algorithm defines a peak (trough) at time $t$ as occurring when the series $\mathrm{y}_{\mathrm{t}}>(<) \mathrm{y}_{\mathrm{t}+2}$ and ensures that peaks and troughs alternate. It also imposes a restriction that a cycle phase lasts at least two quarters and a complete cycle lasts five quarters at a minimum. The algorithm is consistent with the methodology used by the NBER to date business cycles in the United States. In addition to dating cycles, we identify their duration and amplitude (Harding and Pagan, 2002). 


\section{DAta AND DAta Transformations}

\section{A. Data}

We use a panel data set of quarterly macroeconomic and financial series for 20 advanced countries for the period from 1981:Q1 to 2006:Q4. ${ }^{9}$ The data cover indicators of real activity, including consumption, investment, international trade in goods and services; confidence indicators, international portfolio and direct investment flows, consumer prices, as well as financial variables, such as bank credit to the private sector, house prices, stock prices, monetary aggregates, and short- and long-term interest rates. ${ }^{10}$ Also included are selected balance-sheet data, such as household wealth. Besides national variables, the data set includes selected global variables, such as crude oil prices, commodity price index for industrial inputs, world demand, and world reserves. Most of the data series are from the Organization for Economic Cooperation and Development (OECD) database, and a few come from national sources and other international organizations. For a complete list of the data used in the analysis, as well as the data sources, see Appendix I.

\section{B. Unit Root Tests}

For the purposes of the GDFM analysis, data need to be covariance stationary. After removing the seasonal component, we determine the degree of integration of data series. As is well known, unit root tests have low power, and results are sensitive to the specification of unit root tests. We use two tests: the ERS (Elliott, Rothenberg and Stock, 1996) test and the KPSS test (Kwiatowski, Phillips, Schmidt, and Shin, 1992) test. The ERS test is a generalized least squares unit root test, which is more powerful than standard Dickey-Fuller tests. The KPSS test provides a good cross-check on the ERS test, as it uses a different null hypothesis (stationarity, instead of a unit root, as in the ERS test). The unit root tests conducted include a constant and a deterministic trend. ${ }^{11}$ The number of lags is chosen using the Schwarz information criterion and ensuring that no serial correlation is left in the residuals. The results of unit root tests are presented in Table 1.

A striking finding is that house price series for a number of countries (including France, Ireland, the Netherlands, New Zealand, Norway, Sweden, and the United States) are found to be I(2). Credit series are also I(2) for a number of countries, including, notably, Japan and Spain. The degree of integration has implications for policy analysis. For example, if a house price series is I(2), first-differencing it and using it together with other first-

\footnotetext{
${ }^{9}$ The countries included in the analysis are Australia, Austria, Belgium, Canada, Denmark, Finland, France, Germany, Ireland, Italy, Japan, the Netherlands, New Zealand, Norway, Portugal, Spain, Sweden, Switzerland, the United Kingdom, and the United States.

${ }^{10}$ The short- and long-term interest rates are left in nominal terms on the grounds that money illusion may be an important factor in determining the nature of the cyclical movements and linkages among cycles. Brunnermeier and Julliard (2008), for instance, show that nominal house prices are typically boosted when inflation declines.

${ }^{11}$ As most series trend, a trend was included in the null hypothesis. However, in case of doubt, the order-ofintegration analysis was also done excluding the trend and or the constant from the null hypothesis.
} 
differenced series for which the true data generating process (DGP) is I(1) will render spurious results. In contrast, second-differencing a series considered to be I(2) but for which the true DGP is I(1) will result in over-differencing and will weaken the analysis. ${ }^{12}$

\section{Band-Pass Filter}

We use the Corbae-Ouliaris ideal band-pass filter (Corbae and Ouliaris, 2006) to isolate the cyclical component in the data. The filter passes through the components of the time series levels with periodic fluctuations between 6 and 32 quarters - in line with the original specification of Burns and Mitchell (1946) — while removing components at other, higher or lower, frequencies.

Assume that $X_{t}$ is an $\mathrm{I}(1)$ process with $\Delta X_{t}=v_{t}$ such that $v_{t}$ has a Wold representation. The spectral density of $v_{t}$ is $f_{v v}(\lambda)>0$, for all $\lambda$. The discrete Fourier transform of $X_{t}$ for $\lambda_{t} \neq 0$ is

$$
w_{X}\left(\lambda_{s}\right)=\frac{1}{1-e^{i \lambda_{s}}} w_{v}\left(\lambda_{s}\right)-\frac{e^{i \lambda_{s}}}{1-e^{i \lambda_{s}}} \frac{\left(X_{n}-X_{0}\right)}{n^{1 / 2}},
$$

where $\lambda_{s}=\frac{2 \pi s}{n}, \mathrm{~s}=0,1, \ldots, \mathrm{n}-1$, are the fundamental frequencies. The second term makes it clear that the Fourier transform is not asymptotically independent across fundamental frequencies because the second term is a deterministic trend in the frequency domain with a random coefficient of $\frac{\left(X_{n}-X_{0}\right)}{n^{1 / 2}}$. Unless that term is removed, it will produce leakages into all frequencies $\lambda_{t} \neq 0$, even in the limit as $n \rightarrow \infty$. Sacrificing a single observation, instead of estimating the random coefficient à la Hannan (1970), Corbae and Ouliaris (2006) show that by imposing that $\left(X_{n}-X_{1}\right)=\left(X_{n}-X_{0}\right)$ will produce an estimate that will have no finite sampling error, has superior end-point properties, and has much lower mean-squared error than popular time-domain filters such as Hodrick-Prescott or Baxter-King. In addition, in contrast to Baxter-King, it is consistent.

The filtering approach has an important advantage for the purpose of our analysis, as in contrast to alternative ways of obtaining covariance-stationary data (such as differencing for I(1) or I(2) series or detrending for I(0) series with a deterministic trend), it does not remove the portion of the variance that is relevant for the business cycle analysis (see Harvey and Jaeger, 1992, for an illustration of how first differencing affects a series' data generation process). ${ }^{13}$ As an illustration of this point, Figure 1 displays the spectra of the U.S. real

\footnotetext{
${ }^{12}$ One may choose of course to disregard the empirical evidence, taking all house price and credit series to be I(1) simply on the conceptual grounds, but this is not the approach we take in this paper.

${ }^{13}$ Also see Giannone and others (2008) who note that while there is a broad consensus on the synchronization of recessions and expansions on the basis of data on the level of economic activity, there is not at all agreement on the "facts" on growth cycles, i.e., filtered data capturing some longer moving average of growth rates. One
}

(continued...) 
GDP — which contains a unit root according to both ERS and KPSS tests - after filtering the series and after first differencing it. Notice the sizeable loss of variance in the frequency of interest, the business cycle frequency, that results from first differencing, even though, according to the unit root tests, taking the first difference is what is recommended to make this series stationary.

Therefore, while carefully analyzing the statistical properties of the time series, our analysis of the characteristics of the business cycles concentrates on the series made stationary using the Corbae-Ouliaris filter. How data are treated prior to the analysis of cyclical behavior and comovement in the series-whether series are differenced or filtered-has bearing on the conclusions of such analysis. For example, the share of the common variance in the total variance of a series would indicate how important are common explanatory forces in its behavior. Notice that first- and second-differencing results in only 3 percent of all the series displaying a common variance share larger than 20 percent. When the same series are filtered instead, 68 percent of them have a variance share larger than 20 percent. Table 2 summarizes the variance share that is attributable to common components for the series of interest.

Data transformations have not only statistical, but also policy relevance. A wrong data transformation may introduce a downward bias in the degree of comovement between series and the degree of estimated economic integration in structural models embedding those series. As a corollary, it may introduce an upward bias in the efficacy and efficiency of uncoordinated macroeconomic policies. To illustrate, when Dutch house prices are second differenced (the series is found to be $\mathrm{I}(2)$ ), the common variance share is 8 percent; when it is filtered, the common variance share becomes 16 percent. From a policy viewpoint, the correct treatment of the series is important because what may be viewed as a disequilibrium in the housing market - for example, an overvaluation - may simply be a statistical artifact.

In sum, the Corbae-Ouliaris filter, by minimizing distortions to the data generating processes, and in particular by retaining more mass under the spectra at the traditional business cycle and longer periodicities, should allow their intrinsic characteristics to be described in a more robust fashion.

\section{RESUlTS}

Our focus is on the degree of commonality in the cyclical behavior of house prices, credit and real economic activity within and across countries and over time. When presenting results, we first discuss characteristics of the three cycles and comovement between them in the domestic context. Next we evaluate the international comovement of cycles, the importance of common factors in driving them, as well as the role of the United States in leading house price, credit and business cycles in other advanced economies.

important source of surprising differences on descriptive statistics is "lack of robustness with respect to data filtering and statistical methods." Comin and Gertler (2006) also discuss the role of filtering in the literature on economic cycles. 


\section{A. Domestic Cycles}

\section{Characteristics}

Consistent with the predictions of the literature on business cycles and financial accelerators, we find a significant degree of comovement in credit, house prices, and real activity within countries. Figure 2 displays the cyclical portion - the sum of common and idiosyncratic components - of these series. The peaks and troughs of the three cycles often coincide. This is broadly consistent with the analysis of business cycles duration (Table 3) and the view that business cycles are closely related to housing cycles (for example, Leamer, 2007). However, there are also notable differences in the characteristics of cycles across countries.

Although a rigorous analysis of country-specific factors that may explain differences in the cyclical behavior is beyond the scope of this paper, one may attribute cyclical differences to differences in the structure of countries' financial systems and housing markets such as the share of mortgage debt, owner-occupation rates, and the pervasiveness of variable rate mortgages (Table 4). In particular, the possibility of mortgage equity withdrawal and refinancing is likely to fasten and strengthen the transmission of house price shocks to household consumption and bear on the monetary transmission mechanism, with changes in interest rates having a stronger effect on households' cash flow, consumption and output. Differences in the price elasticity of housing supply may also be contributing to differences in the amplitudes of cycles. If the supply elasticity is low, house prices would tend to respond strongly to changes in interest rates, with knock-on effects on wealth and consumption.

\section{Correlations}

The signs of correlations between house prices, credit, and output are generally positive, consistent with the financial accelerator theories and the procyclicality of credit and house price behavior (Table 5). However, the magnitude of correlations (and in a few cases even their sign) vary across countries. This implies that the financial accelerator mechanisms vary across countries, which may explain conflicting empirical evidence on the importance of such mechanisms in different countries. House prices and output generally have a stronger positive comovement than credit and output, for example, in the United States, Denmark, and Spain. This may imply that mortgage market regulations in those countries result in collateral house prices becoming a more important source of procyclicality than bank credit. House prices and bank credit tend to be positively correlated, although in some countries this correlation is much weaker than in others, possibly reflecting a greater importance of mortgage securitization.

\section{Leads and Lags}

Over the short and medium term, the relationship between house prices, credit and output is mixed and varies considerably across countries. Output leads house prices in 17 percent of countries and is contemporaneous with them in 39 percent of countries; in 44 percent of countries house prices lead output instead (Table 7). Output also leads credit in 44 percent of countries and is contemporaneous in 17 percent of countries, while lagging in 39 
percent of countries. If house price and credit bubbles exist (as may be suspected in countries where house prices or credit lead output), the data do not support the generality of the phenomenon.

House prices lead credit in about 50 percent of countries, are contemporaneous in 22 percent of countries, and lag credit in 28 percent of countries (Table 7). This finding points to significant cross-country differences in the financial accelerator mechanisms, in whether the dominant channel relates to increases in house prices, which improve creditworthiness of borrowers and allow them to borrow more, or instead, to greater availability of credit, owing to improvements in bank balance sheets, or both. The identified pattern of leads and lags suggests the importance of the channel of transmission that starts from improvements in banks' balance sheets, and via more abundant credit, boosts house prices.

A much debated current policy issue is how central banks should incorporate house prices or credit in their monetary policy frameworks. The answer will vary across countries given considerable variation in the role of house prices and credit in various economies. Short-term interest rates and house prices are contemporaneous as frequently as house prices lead interest rates; interest rates lag credit in 72 percent of countries, and in most other countries are contemporaneous. ${ }^{14}$ The finding that short-term interest rates never lead house prices and rarely lead credit is potentially important. One interpretation is that during the period covered by the study monetary policy has not been used to actively influence house prices and credit, even in countries and regions that include monetary and credit aggregates, in addition to prices, as "pillars" into their monetary policy frameworks (for example, the euro area and Japan). It cannot be precluded, on the other hand, that the finding reflects the ineffectiveness of monetary policy in influencing house prices and credit. In this context, it is noteworthy that house prices are found to lead credit, real activity, and interest rates in many countries that have experienced a significant run-up in house prices before the current crisis, for example, the Netherlands, Spain, the United Kingdom, and the United States. ${ }^{15}$

In the long run, house prices lead output, interest rates, and credit unequivocally, consistent with the financial accelerator theory that stresses the dominant role of asset prices in the propagation of shocks. More specifically, house prices tend to lead output, which then leads credit. The fact that house prices and credit are not coincident over the long run may suggest that long-term trends in house prices are mostly driven by fundamentals, e.g., increased migration (which raises the demand for housing and drives construction and

\footnotetext{
${ }^{14}$ Interest rates lag real output in 66 percent of the countries in the sample and are contemporaneous in the remainder of the cases. This result can be consistent with different models of monetary policy. For example, interest rates may lag output because changes in them are fully anticipated by forward-looking economic agents. Alternatively, interest rates may lag output because monetary policymakers are not forward looking enough or, while less likely, because they do not factor growth in their policy reaction function.

${ }^{15}$ Another noteworthy finding concerning the relationship between interest rates, on the one hand, and house prices or credit, on the other, is that the lead-lag relationships vary across countries in the eurozone. This suggests that relying on monetary policy alone to discourage rapid increases in house prices and credit may not be effective. Fiscal policies and regulatory policies, set at the national level, may be needed to support monetary policy objectives.
} 
residential investment and demand for credit) or zoning requirements. ${ }^{16}$ Over the long term, there is not much evidence of monetary policy effectiveness in influencing output, credit and house price dynamics, as interest rates clearly lag real activity, credit, and house prices.

\section{B. International Comovement of Cycles}

\section{Common Components}

A large share of a common component driving the three cycles in most countries suggests that cycles tend to be driven by common shocks (for example, oil price changes) or that shocks to one country are quickly transmitted to other countries (Figure 3). This finding is consistent with results in the literature that in a global economy not only international trade but financial markets are important channels of the international transmission of shocks (for example, Kose and others, 2006 and 2008; and Belke and Orth, 2008). A large share of a common component in the house price cycle may reflect common monetary policy shocks, owing to (indirectly) coordinated monetary policy (Otrok and Terrones, 2005), or financial globalization that eliminates interest rate differentials. Different economic structures-for example, the degree of reliance on commodity exports, openness, diversification, and regulatory frameworks for the financial sector and mortgage markets - may explain crosscountry differences in the cyclical behavior, as reflected in the idiosyncratic components of variables and the different factor loadings of the common components.

The common components of the three cycles have evolved over time within individual countries (Table 6). For example, there is some evidence of increased commonality in credit and business cycles in the United States since the 1990s. Overall, in 70 percent of country-cycle pairs, common component has accounted for more of the cyclical movement in the 2000s than it had in the 19080s. Possible explanations include financial innovation and integration, which have relaxed liquidity constraints for households and firms and encouraged greater reliance on wholesale funding. The increased commonality is observed also in other countries, albeit to a lesser extent. A striking feature is the negative comovement of the common component of house prices, on the one hand, and the common components of output and credit, on the other hand, in Germany over the whole sample period, consistent with the findings of the negative correlations in the respective cycles reported in Table 5.

\section{Leads and Lags}

From an international perspective, a key question is whether some countries play a leading role in the transmission of business cycles and house price and credit cycles around the world. We find that the U.S. cycles tend to lead the corresponding cycles in other countries over the long term (Table 8). The U.S. house price cycle leads other countries'

\footnotetext{
${ }^{16}$ Without introducing structure, it is not possible to conduct further analysis. However, the lead-lag relations at the country level can be useful in modeling countries' idiosyncrasies.
} 
house price cycles over the entire time horizon. ${ }^{17}$ The U.S. business cycle also leads business cycles in most other countries. ${ }^{18}$ One of the reasons for such a strong leading relationship seems to be that changes in the U.S. policy rates tend to lead interest rate changes in other countries. In contrast to business cycles, house prices cycles and interest rate cycles, the U.S. credit cycle leads other countries' credit cycles only over the medium to long-term horizon. Over the short term, the credit cycle is contemporaneous in a majority of cases.

The finding of a leading role of the U.S. cycles in global cycles is in line with the literature (for example, Eickmeier, 2007; Kabundi and Nadal De Simone, 2007a). However, the result that credit developments in the United States are not a driving factor in many countries over the short to medium term underscores the challenges of drawing policy implications - the decision on how much weight to give to U.S. credit developments in monetary analysis is likely to depend on the time horizon one concentrates on. Only U.S. business cycle and house price cycle seem to be unambiguously important determinants of cyclical developments in other countries.

\section{CONCLusion}

This paper highlights the complexity and diversity of cyclical comovements in house prices, credit and output, and hence the challenge of modeling them to draw policy prescriptions. Most importantly, our findings help explain the lack of consensus in several strands of the empirical literature, for example, on whether credit booms are speculative or fundamentals-driven; whether there are house price "bubbles" and how effective domestically-focused macroeconomic policies are likely to be. Answers to these questions depend on the relationships between the three cycles, which tend to shift over time and vary across countries. (Our sample consists of advanced countries, and even greater differences could be expected in a broader sample including emerging and developing economies). Data transformations used to make series stationary may also contribute to disparate empirical findings in the literature.

A related implication of the paper is that uniform policy prescriptions concerning, for example, taking into account asset prices in monetary policymaking, could be problematic. Although some general patterns can be identified, the degree of comovement between house prices, credit, and output varies considerably across countries and even within individual countries over time. Statistical properties of house price series also differ across countries. In some countries, shocks to house price inflation are persistent, which would complicate the stabilization of house price inflation, if it were to become the central bank's objective.

Finally, the paper also underscores the high degree of commonality in national cycles in all three variables while highlighting the leading role of economic activity in the United States. This finding may be a reflection of the important role of the United States in the

\footnotetext{
${ }^{17}$ Exceptions are Germany, Japan and Norway, for reasons that are probably easy to identify: Germany's unification, Japan's financial crisis and "the lost decade", and Norway's heavy dependence of oil.

${ }^{18}$ Exceptions are Australia, Ireland, New Zealand, Norway, and Switzerland.
} 
global economy and the global financial system, as well as increased trade and financial integration among advanced economies. Increased international linkages naturally call for greater policy coordination, and the data suggests that to some extent such policy coordination is already taking place through common movements in policy variables, particularly interest rates. 
Figure 1. Filtered versus Differenced Series

( $\mathrm{Y}$ axis: spectrum; $\mathrm{X}$ axis: periodicities in quarters)

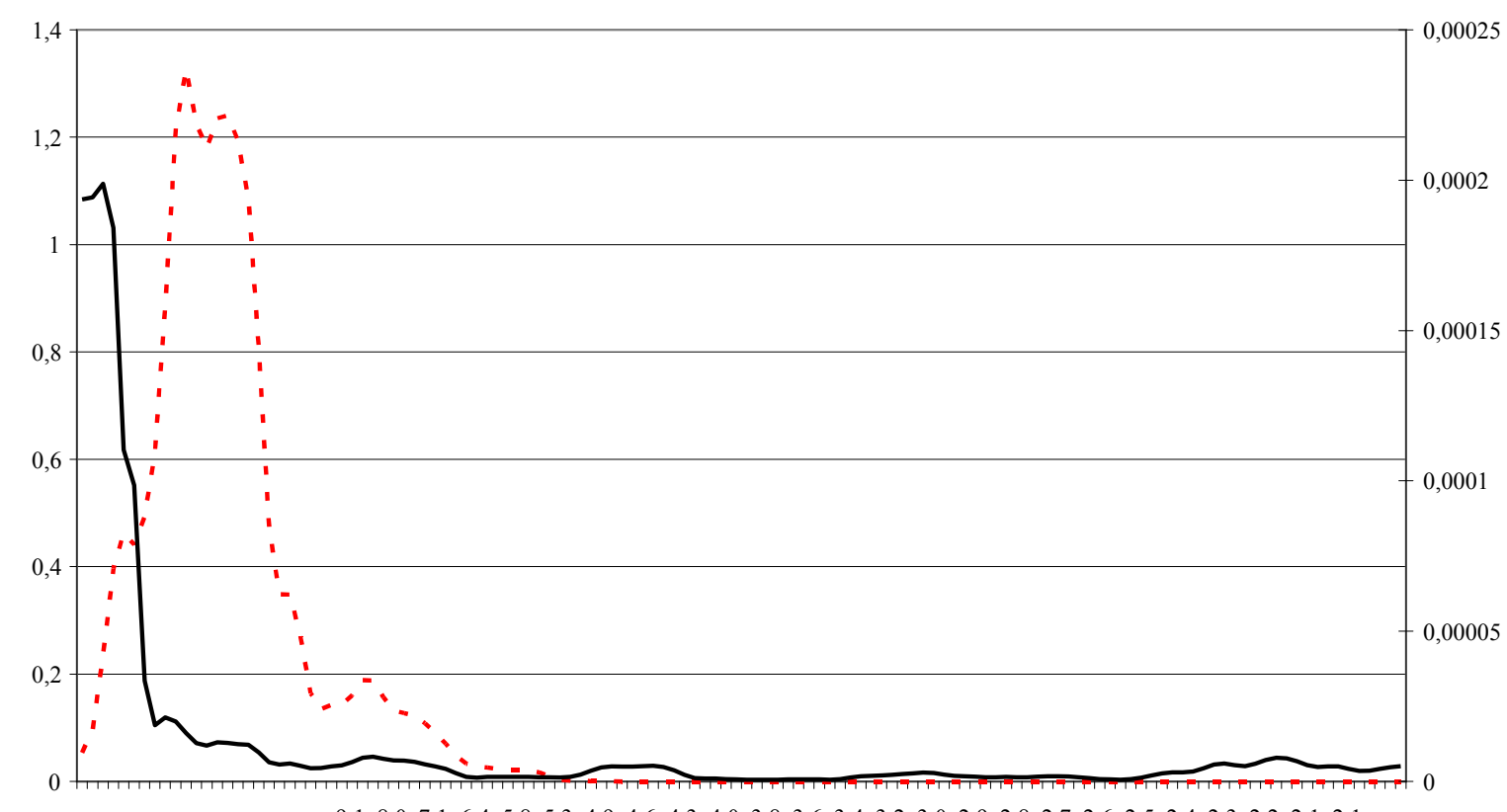

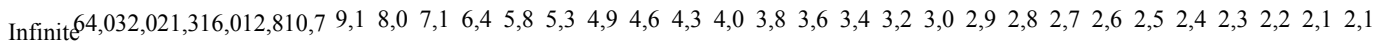

- - - GDP Ideal Band Pass, Corbae-Ouliaris Filter $\quad$ - GDP First Differenced (RHS) 
Figure 2. Total Cyclical Movements of Real GDP, Credit and House Prices
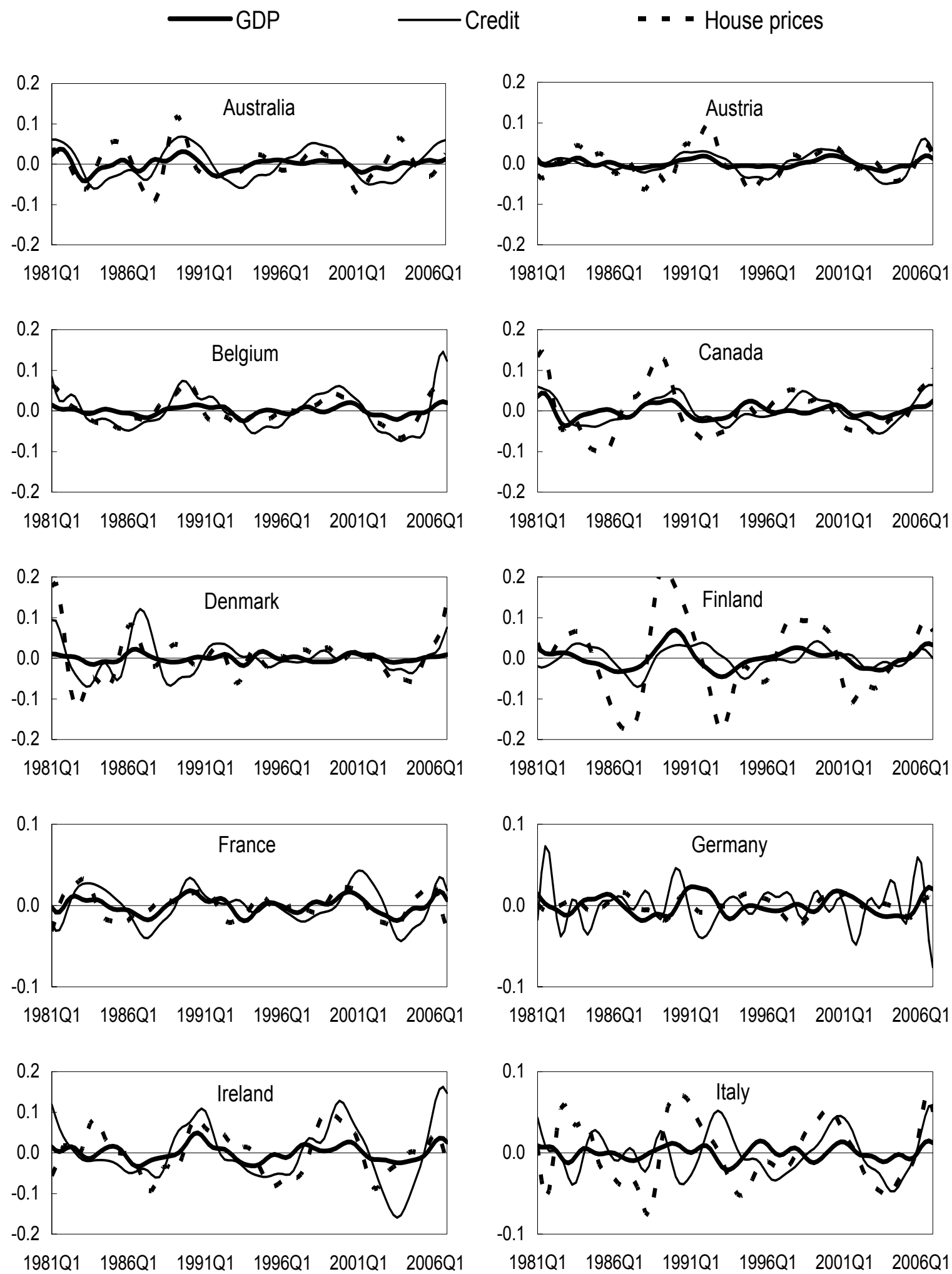
Figure 2. Total Cyclical Movements of Real GDP, Credit and House Prices - Continued

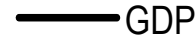

0.1
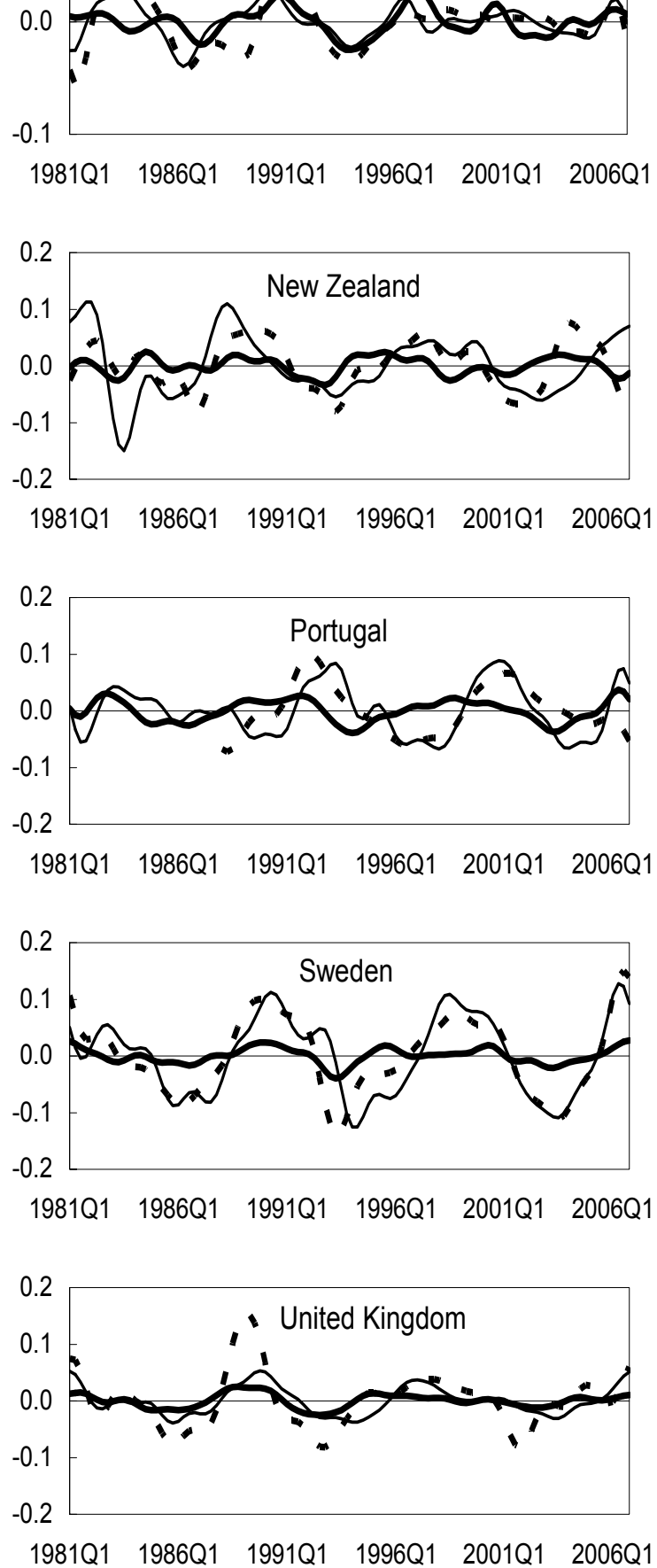

- - House prices
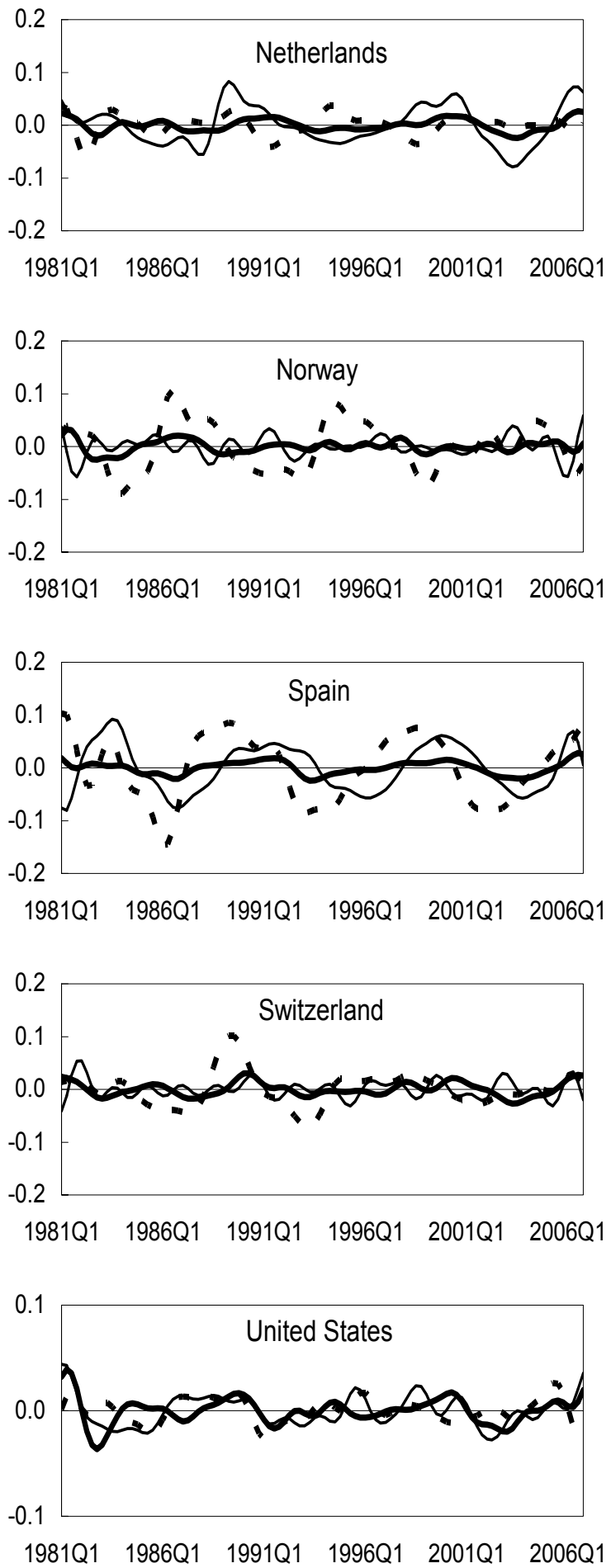
Figure 3. Total Cyclical Movement versus Common Components in Selected Countries Real GDP
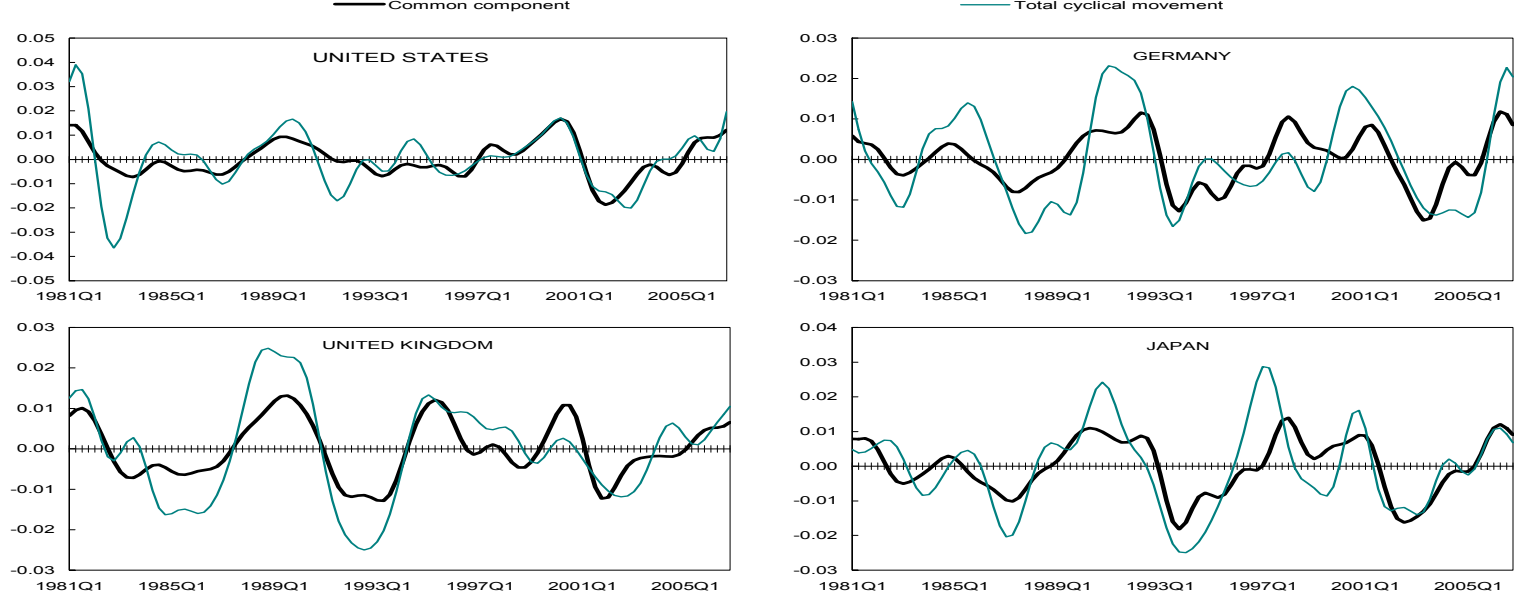

Credit
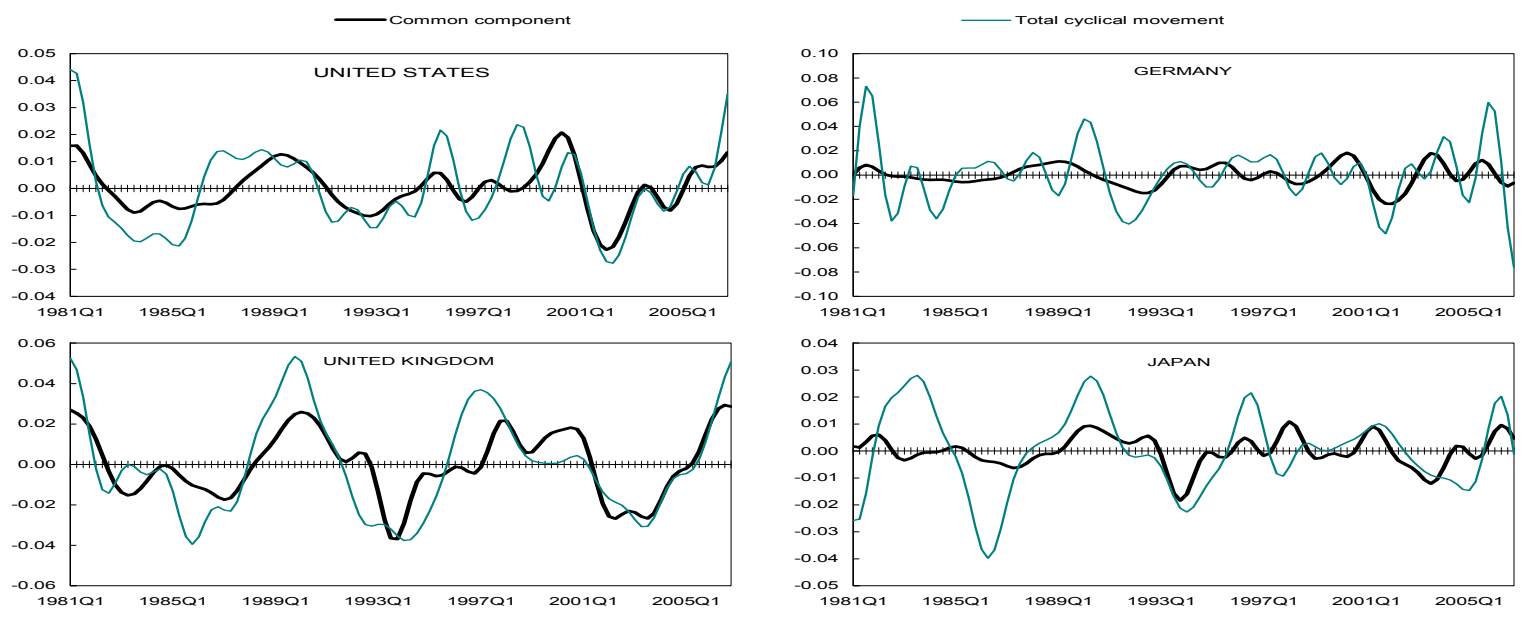

House Prices
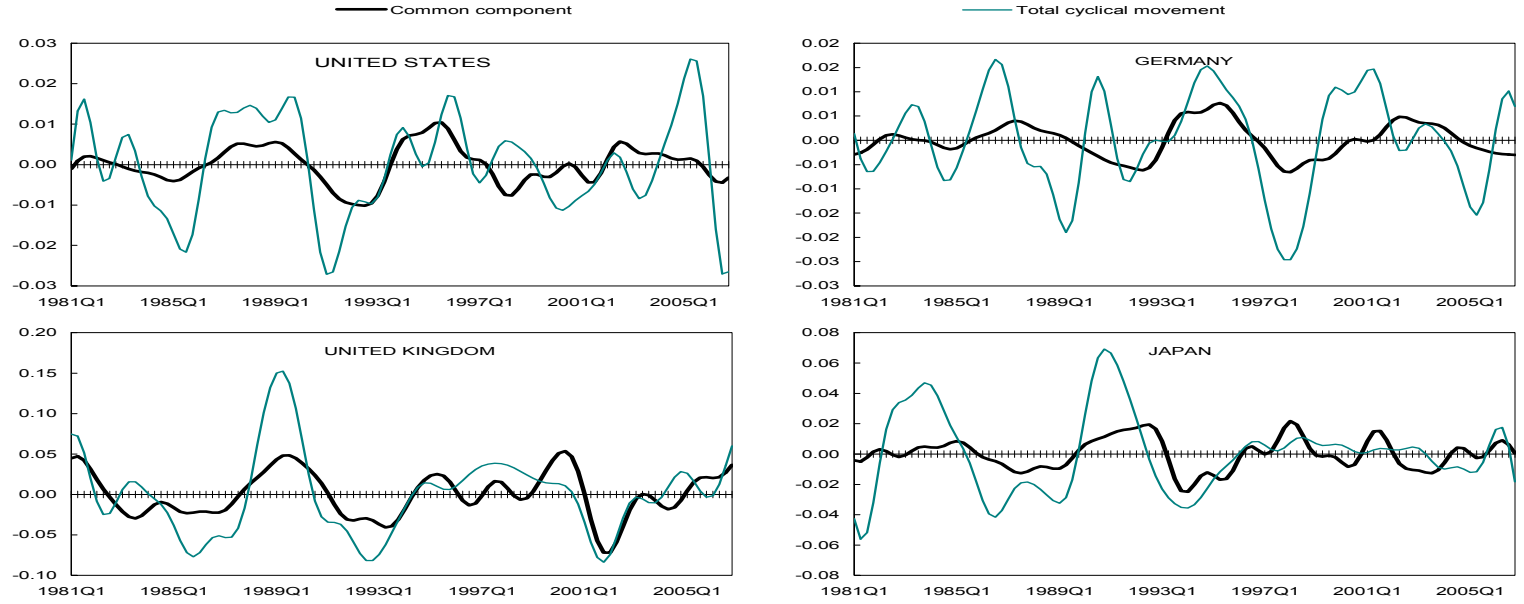
Figure 4. Common Components for Selected Countries
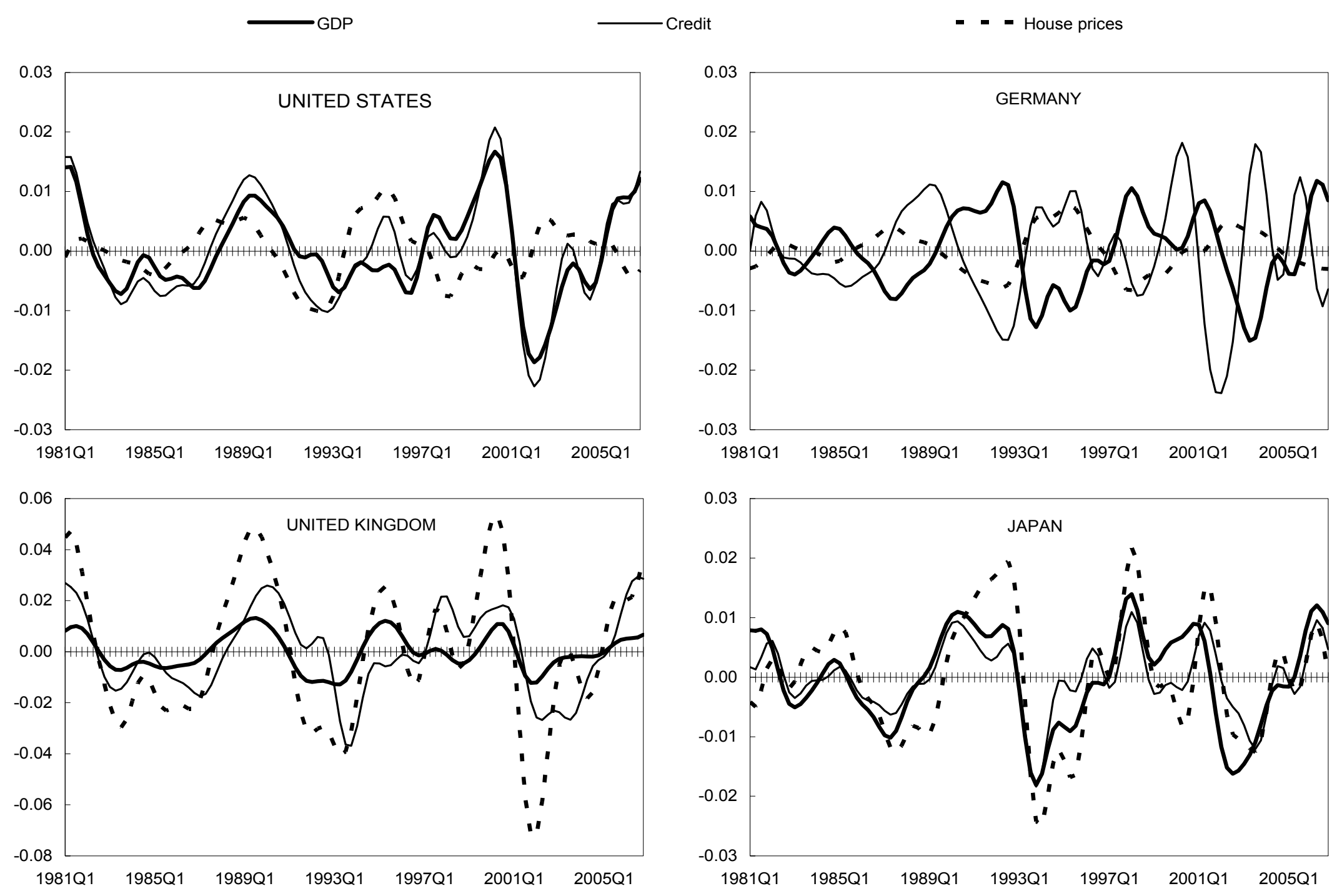
Table 1. Unit Root Tests

\begin{tabular}{|c|c|c|c|c|c|c|c|c|c|}
\hline & \multicolumn{3}{|c|}{ Output } & \multicolumn{3}{|c|}{ House Prices } & \multicolumn{3}{|c|}{ Credit } \\
\hline & $E R S$ & KPSS & $\begin{array}{l}\text { Decision in Cases of } \\
\text { Conflicting Evidence }\end{array}$ & $E R S$ & KPSS & $\begin{array}{l}\text { Decision in Cases of } \\
\text { Conflicting Evidence }\end{array}$ & $E R S$ & KPSS & $\begin{array}{l}\text { Decision in Cases of } \\
\text { Conflicting Evidence }\end{array}$ \\
\hline Australia & $\mathrm{I}(1)$ & $\mathrm{I}(1)$ & & $\mathrm{I}(1)$ & $\mathrm{I}(1)$ & & $\mathrm{I}(1)$ & $\mathrm{I}(1)$ & \\
\hline Austria & $\mathrm{I}(1)$ & $\mathrm{I}(1)$ & & $\mathrm{I}(1)$ & $\mathrm{I}(2)$ & $\mathrm{I}(2)^{1,5}$ & $\mathrm{I}(0)$ & $\mathrm{I}(1)$ & $\mathrm{I}(1)^{1,5}$ \\
\hline Belgium & $\mathrm{I}(0)$ & $\mathrm{I}(1)$ & $\mathrm{I}(1)^{2}$ & $\mathrm{I}(1)$ & $\mathrm{I}(1)$ & & $\mathrm{I}(1)$ & $\mathrm{I}(1)$ & \\
\hline Canada & $\mathrm{I}(1)$ & $\mathrm{I}(1)$ & & $\mathrm{I}(1)$ & $\mathrm{I}(1)$ & & $\mathrm{I}(1)$ & $\mathrm{I}(1)$ & \\
\hline Denmark & $\mathrm{I}(1)$ & $\mathrm{I}(1)$ & & $\mathrm{I}(1)$ & $\mathrm{I}(1)$ & & $\mathrm{I}(1)$ & $\mathrm{I}(1)$ & \\
\hline Finland & $\mathrm{I}(0)$ & $\mathrm{I}(1)$ & $\mathrm{I}(1)$ & $\mathrm{I}(1)$ & $\mathrm{I}(1)$ & & $\mathrm{I}(2)$ & $\mathrm{I}(2)$ & \\
\hline France & $\mathrm{I}(1)$ & $\mathrm{I}(1)$ & & $\mathrm{I}(2)$ & $\mathrm{I}(2)$ & & $\mathrm{I}(2)$ & $\mathrm{I}(2)$ & \\
\hline Germany & $\mathrm{I}(1)$ & $\mathrm{I}(1)$ & & $\mathrm{I}(1)$ & $\mathrm{I}(1)$ & & $\mathrm{I}(1)$ & $\mathrm{I}(2)$ & $\mathrm{I}(2)^{1,5}$ \\
\hline Ireland & $\mathrm{I}(1)$ & $\mathrm{I}(2)$ & $\mathrm{I}(1)^{1}$ & $\mathrm{I}(1)$ & $\mathrm{I}(2)$ & $\mathrm{I}(2)^{1,5}$ & $\mathrm{I}(1)$ & $\mathrm{I}(1)$ & \\
\hline Italy & $\mathrm{I}(1)$ & $\mathrm{I}(1)$ & & $\mathrm{I}(0)$ & $\mathrm{I}(2)$ & $\mathrm{I}(0)^{1}$ & $\mathrm{I}(1)$ & $\mathrm{I}(1)$ & \\
\hline Japan & $\mathrm{I}(1)$ & $\mathrm{I}(2)$ & $\mathrm{I}(1)^{1}$ & $\mathrm{I}(1)$ & $\mathrm{I}(1)$ & & $\mathrm{I}(2)$ & $\mathrm{I}(2)$ & \\
\hline Netherlands & $\mathrm{I}(1)$ & $\mathrm{I}(1)$ & & $\mathrm{I}(1)$ & $\mathrm{I}(2)$ & $\mathrm{I}(2)^{1,5}$ & $\mathrm{I}(1)$ & $\mathrm{I}(1)$ & \\
\hline New Zealand & $\mathrm{I}(1)$ & $\mathrm{I}(1)$ & & $\mathrm{I}(1)$ & $\mathrm{I}(2)$ & $\mathrm{I}(2)^{1,5}$ & $\mathrm{I}(1)$ & $\mathrm{I}(1)$ & \\
\hline Norway & $\mathrm{I}(1)$ & $\mathrm{I}(1)$ & & $\mathrm{I}(1)$ & $\mathrm{I}(2)$ & $\mathrm{I}(2)^{1,5}$ & $\mathrm{I}(0)$ & $\mathrm{I}(2)$ & $\mathrm{I}(2)^{5}$ \\
\hline Portugal & $\mathrm{I}(1)$ & $\mathrm{I}(1)$ & & $\mathrm{I}(0)$ & $\mathrm{I}(1)$ & $\mathrm{I}(1)^{1,5}$ & $\mathrm{I}(1)$ & $\mathrm{I}(1)$ & \\
\hline Spain & $\mathrm{I}(1)$ & $\mathrm{I}(1)$ & & $\mathrm{I}(1)$ & $\mathrm{I}(1)$ & & $\mathrm{I}(2)$ & $\mathrm{I}(2)$ & \\
\hline Sweden & $\mathrm{I}(1)$ & $\mathrm{I}(1)$ & & $\mathrm{I}(1)$ & $\mathrm{I}(2)$ & $\mathrm{I}(1)^{1,5}$ & $\mathrm{I}(1)$ & $\mathrm{I}(1)$ & \\
\hline Switzerland & $\mathrm{I}(1)$ & $\mathrm{I}(1)$ & & $\mathrm{I}(1)$ & $\mathrm{I}(1)$ & & $\mathrm{I}(1)$ & $\mathrm{I}(2)$ & $\mathrm{I}(2)^{1}$ \\
\hline United Kingdom & $\mathrm{I}(1)$ & $\mathrm{I}(1)$ & & $\mathrm{I}(1)$ & $\mathrm{I}(1)$ & & $\mathrm{I}(0)$ & $\mathrm{I}(1)$ & $\mathrm{I}(1)^{1,5}$ \\
\hline United States & $\mathrm{I}(1)$ & $\mathrm{I}(1)$ & & $\mathrm{I}(2)$ & $\mathrm{I}(2)$ & & $\mathrm{I}(1)$ & $\mathrm{I}(1)$ & \\
\hline
\end{tabular}

Source: Authors' estimates.

Note: Highlighting indicates differences in test results.

1. The charts do suggest that stationarity is only achieved at the specified differenced series

2. The ERS test barely passes the confidence level.

3. Schwarz criterion suggests taking 3 lags and there is no SC either with 1 or 2 lags. Three lags suggest I(1).

4. The KPSS test barely passes the confidence level. In addtion, observation of the series suggests that it contains a unit root.

5. When the ERS test on first differences does reject the I(1) null, a relatively higher error of type I is assumed for KPSS test (1 percent). 
Table 2. Variance Shares 1/

\begin{tabular}{lcc}
\hline & Differenced Series & Filtered Series \\
\hline Average & 0.07 & 0.31 \\
Maximum & 0.18 & 0.70 \\
Minimum & 0.01 & 0.01 \\
Standard deviation & 0.04 & 0.17 \\
Coefficient of variation & 0.62 & 0.55 \\
Variance share exceeding 20 percent 2/ & 0.00 & 0.68 \\
\hline
\end{tabular}

Source: Authors' estimates.

$1 /$ The share of variance explained by common components for house prices, credit, output, shortand long-term interest rates.

2/ Number of series, in percent of the total number of series. 
Table 3. Cycle Characteristics

\begin{tabular}{|c|c|c|c|c|c|c|c|c|c|c|c|c|}
\hline & \multicolumn{2}{|c|}{ Peak-to-trough } & \multicolumn{2}{|c|}{ Trough-to-peak } & \multicolumn{2}{|c|}{ Peak-to-trough } & \multicolumn{2}{|c|}{ Trough-to-peak } & \multicolumn{2}{|c|}{ Peak-to-trough } & \multicolumn{2}{|c|}{ Trough-to-peak } \\
\hline & Duration & Amplitude & Duration & Amplitude & Duration & Amplitude & Duration & Amplitude & Duration & Amplitude & Duration & Amplitude \\
\hline & & & & & & House & rices & & & Cre & & \\
\hline Australia & 5 & -71.5 & 7 & 72.0 & 6 & -67.2 & 5 & 65.3 & 7 & -94.2 & 5 & 88.5 \\
\hline Austria & 6 & -79.7 & 7 & 84.1 & 5 & -76.1 & 8 & 73.7 & 6 & -65.5 & 8 & 86.8 \\
\hline Belgium & 6 & -95.2 & 10 & 102.0 & 6 & -109.8 & 9 & 140.0 & 6 & -86.3 & 6 & 79.5 \\
\hline Canada & 6 & -83.3 & 9 & 71.5 & 5 & -67.1 & 10 & 65.9 & 7 & -116.4 & 8 & 128.2 \\
\hline Denmark & 7 & -114.5 & 6 & 117.7 & 6 & -112.7 & 7 & 105.8 & 5 & -60.9 & 7 & 58.1 \\
\hline Finland & 7 & -150.4 & 8 & 131.8 & 9 & -123.8 & 6 & 128.2 & 6 & -107.2 & 7 & 96.5 \\
\hline France & 5 & -92.6 & 10 & 105.7 & 6 & -82.6 & 7 & 93.5 & 8 & -120.9 & 8 & 120.3 \\
\hline Germany & 5 & -84.4 & 7 & 95.7 & 6 & -103.7 & 7 & 111.4 & 7 & -62.4 & 13 & 68.3 \\
\hline Ireland & 7 & -110.9 & 6 & 114.7 & 8 & -155.2 & 7 & 144.7 & 5 & -84.7 & 10 & 110.9 \\
\hline Italy & 5 & -66.5 & 7 & 59.0 & 8 & -136.8 & 9 & 146.7 & 7 & -118.6 & 9 & 130.5 \\
\hline Japan & 5 & -82.3 & 9 & 84.9 & 6 & -105.9 & 7 & 61.4 & 5 & -141.5 & 9 & 127.9 \\
\hline Netherlands & 7 & -92.9 & 9 & 88.3 & 6 & -89.1 & 5 & 76.4 & 7 & -109.3 & 8 & 115.2 \\
\hline New Zealand & 6 & -57.0 & 6 & 56.6 & 5 & -101.9 & 10 & 120.2 & 6 & -90.1 & 6 & 83.0 \\
\hline Norway & 7 & -73.1 & 11 & 39.1 & 6 & -86.0 & 6 & 83.3 & 7 & -57.5 & 14 & 92.6 \\
\hline Spain & 6 & -106.6 & 11 & 117.9 & 7 & -110.1 & 8 & 93.6 & 8 & -117.5 & 8 & 103.6 \\
\hline Switzerland & 5 & -103.2 & 6 & 104.9 & 4 & -54.8 & 8 & 55.0 & 3 & -58.4 & 37 & 135.4 \\
\hline United Kingdom & 5 & -61.9 & 9 & 84.6 & 6 & -103.9 & 8 & 82.0 & 6 & -133.1 & 9 & 114.8 \\
\hline United States & 5 & -103.2 & 7 & 63.6 & 7 & -61.5 & 6 & 93.2 & 4 & -62.8 & 6 & 44.2 \\
\hline Average & 6 & -90.5 & 8 & 88.6 & 6 & -97.1 & 7 & 96.7 & 6 & -93.7 & 10 & 99.1 \\
\hline Median & 6 & -88.5 & 8 & 86.6 & 6 & -102.8 & 7 & 93.4 & 6 & -92.2 & 8 & 100.1 \\
\hline
\end{tabular}

Source: Authors' estimates.

Note: All in percent except duration. Duration is the number of quarters between two consecutive peaks (or troughs). Amplitude is the output contraction (or expansion) from peak (trough) to trough (peak). 
Table 4. Characteristics of Mortgage Markets

\begin{tabular}{|c|c|c|c|c|c|c|}
\hline & $\begin{array}{c}\text { Mortgage } \\
\text { Equity } \\
\text { Withdrawal }\end{array}$ & Refinancing & $\begin{array}{c}\text { Mortgage } \\
\text { Interest Tax } \\
\text { Relief }\end{array}$ & $\begin{array}{c}\text { Share of Fixed } \\
\text { Rate Mortgages } \\
1 /\end{array}$ & $\begin{array}{c}\text { Home } \\
\text { Ownership } \\
\text { Ratio 1/ } \\
\end{array}$ & $\begin{array}{c}\text { Residential } \\
\text { Mortgage Debt } \\
\text { Outstanding 2/ } \\
\end{array}$ \\
\hline Australia & Yes & Partially & No & 16 & 70 & 51 \\
\hline Austria & No & No & Partially & 75 & 56 & 20 \\
\hline Belgium & No & No & Partially & 75 & 68 & 30 \\
\hline Canada & Partially & No & No & 71 & 65 & 43 \\
\hline Denmark & Yes & Yes & Yes & 70 & 52 & 88 \\
\hline Finland & Yes & No & Partially & 7 & 64 & 39 \\
\hline France & No & No & No & 68 & 55 & 26 \\
\hline Germany & No & No & No & 84 & 44 & 52 \\
\hline Ireland & Partially & Yes & Partially & 15 & 77 & 52 \\
\hline Italy & No & No & Partially & 22 & 74 & 15 \\
\hline Japan & Partially & Partially & Partially & 78 & 60 & 37 \\
\hline Netherlands & Yes & No & Yes & 64 & 53 & 89 \\
\hline New Zealand & Yes & Yes & No & 67 & 77 & 55 \\
\hline Norway & Yes & No & Partially & 10 & 78 & 50 \\
\hline Portugal & No & No & Partially & 5 & 73 & 50 \\
\hline Spain & Partially & No & Partially & 7 & 82 & 46 \\
\hline Sweden & Yes & No & Yes & 50 & 46 & 52 \\
\hline Switzerland & No & Yes & Partially & 72 & 35 & 102 \\
\hline United Kingdom & Yes & Partially & No & 28 & 69 & 75 \\
\hline United States & Yes & Yes & Partially & 65 & 67 & 58 \\
\hline
\end{tabular}

Source: Global Property Guide, European Mortgage Federation, and national sources.

$1 /$ In percent.

2/ In percent of GDP.

Table 5. Correlation Coefficients for Total Cyclical Components

\begin{tabular}{lccc}
\hline & Output-House Prices & Output-Credit & Credit-House Prices \\
\hline Australia & 0.37 & 0.35 & 0.18 \\
Austria & -0.10 & 0.13 & 0.04 \\
Belgium & 0.34 & 0.21 & 0.22 \\
Canada & 0.35 & 0.63 & 0.34 \\
Denmark & 0.52 & 0.11 & 0.38 \\
Finland & 0.58 & 0.32 & 0.25 \\
France & 0.32 & 0.35 & 0.55 \\
Germany & 0.04 & -0.04 & 0.49 \\
Ireland & 0.30 & -0.08 & 0.44 \\
Italy & 0.09 & 0.15 & 0.53 \\
Japan & 0.33 & 0.08 & 0.52 \\
Netherlands & 0.32 & 0.35 & 0.71 \\
New Zealand & 0.27 & 0.05 & 0.23 \\
Norway & 0.32 & 0.26 & -0.32 \\
Spain & 0.42 & 0.18 & 0.46 \\
Switzerland & 0.11 & 0.07 & -0.02 \\
United Kingdom & 0.39 & -0.04 & 0.56 \\
United States & 0.50 & 0.18 & 0.13 \\
Mean & & & 0.32 \\
\hline
\end{tabular}

Source: Authors' estimates. 
Table 6. Leads and Lags between Cycles within Countries 1/

\begin{tabular}{|c|c|c|c|c|c|c|c|c|c|c|c|c|}
\hline \multirow[b]{2}{*}{ Country } & \multicolumn{2}{|c|}{ Credit-Output } & \multicolumn{2}{|c|}{ Credit-House Prices } & \multicolumn{2}{|c|}{ Output-House Prices } & \multicolumn{2}{|c|}{ Interest Rates-Credit } & \multicolumn{2}{|c|}{ Interest Rates-Output } & \multicolumn{2}{|c|}{ Interest Rates-House Prices } \\
\hline & 6-16 quarters & 16-32 quarters & 6-16 quarters & 16-32 quarters & 6-16 quarters & 16-32 quarters & 6-16 quarters & 16-32 quarters & 6-16 quarters & 16-32 quarters & 6-16 quarters & 16-32 quarters \\
\hline Australia & lag & lag & contemp. & lag & contemp. & lag & lag & lead & lag & lag & contemp. & lag \\
\hline Austria & lead & lag & lead & lead & contemp. & lead & lag & lead & lag & lag & contemp. & lead \\
\hline Canada & lag & lag & lag & lag & lag & contemp. & lag & lead & lag & lag & lag & lag \\
\hline Denmark & lead & lead & lead & lag & lag & lag & lag & lead & lag & lag & lag & lag \\
\hline Finland & lag & lag & lag & lag & lag & lag & contemp. & contemp. & contemp. & lag & lag & lag \\
\hline France & contemp. & lag & lag & lag & lag & lag & contemp. & contemp. & lag & lag & lag & lag \\
\hline Ireland & lead & lead & lead & lead & lead & lead & lag & lag & contemp. & lag & contemp. & lead \\
\hline Italy & lead & lag & lead & lag & contemp. & lead & lag & lead & contemp. & lag & contemp. & contemp. \\
\hline Japan & lag & lead & contemp. & lead & lead & lead & contemp. & lag & lag & lag & contemp. & contemp. U \\
\hline Netherlands & contemp. & lead & lag & lag & lag & lag & lag & lag & lag & lag & lag & lag \\
\hline New Zealand & lag & lag & contemp. & lag & lead & lead & lag & contemp. & lead & lag & lag & contemp. \\
\hline Norway & lead & lead & lead & lead & lag & lead & lead & lead & contemp. & lag & contemp. & lag \\
\hline Spain & lag & lag & lag & lag & contemp. & lag & lag & lead & lag & lag & lag & lag \\
\hline Switzerland & contemp. & lead & lag & lead & contemp. & lag & lag & lag & lag & lag & contemp. & lag \\
\hline United Kingdom & lead & lag & lag & lag & contemp. & contemp. & lag & lag & lag & lag & lag & lag \\
\hline Contemporaneous & $17 \%$ & $11 \%$ & $22 \%$ & $6 \%$ & $39 \%$ & $11 \%$ & $22 \%$ & $17 \%$ & $28 \%$ & $6 \%$ & $50 \%$ & $17 \%$ \\
\hline Leads & $39 \%$ & $39 \%$ & $28 \%$ & $28 \%$ & $17 \%$ & $33 \%$ & $6 \%$ & $39 \%$ & $6 \%$ & $0 \%$ & $0 \%$ & $17 \%$ \\
\hline Lags & $44 \%$ & $50 \%$ & $50 \%$ & $66 \%$ & $44 \%$ & $56 \%$ & $72 \%$ & $44 \%$ & $66 \%$ & $94 \%$ & $50 \%$ & $67 \%$ \\
\hline
\end{tabular}

Source: Authors' estimates.

1/ For each pair listed in the title, entries in the table indicate whether the first variable leads or lags the second variable, or whether the relationship is contemporaneous, on average, over the frequency band. 
Table 7. Evolution of Cyclical Movements Driven by Common Components

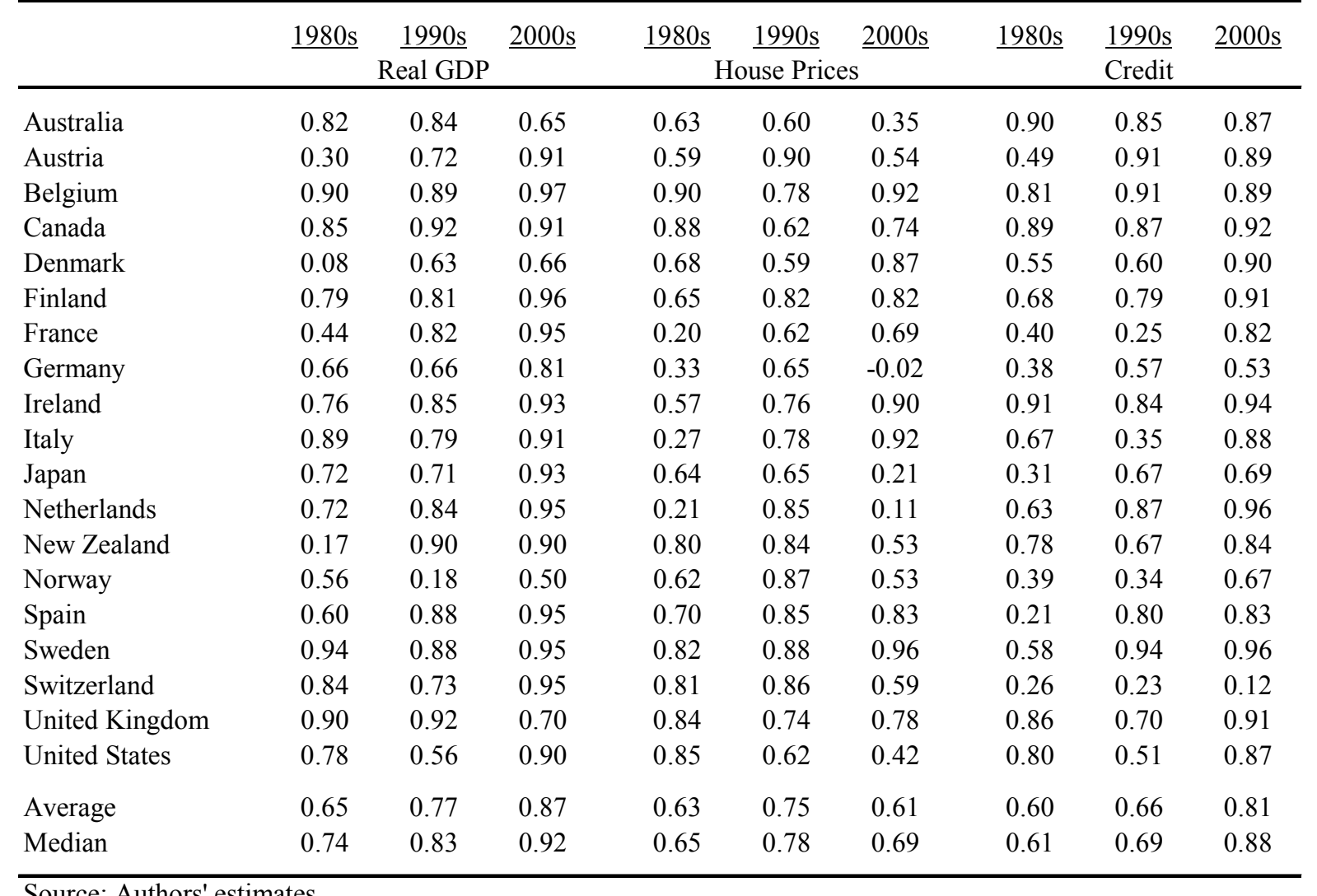

Source: Authors' estimates.

Note: The statistics reported are the correlation coefficients for total cyclical movement (shown in Figure 2) and the common component (shown in Figure 4). 
Table 8. Lead-Lag Relations between the United States and Other Countries

\begin{tabular}{|c|c|c|c|c|c|c|c|c|}
\hline \multirow[t]{2}{*}{ Countries } & \multicolumn{2}{|c|}{ House prices } & \multicolumn{2}{|c|}{ Credit } & \multicolumn{2}{|c|}{ Real GDP } & \multicolumn{2}{|c|}{ Short-term interest rates } \\
\hline & 8-16 quarters & 16-32 quarters & 8-16 quarters & 16-32 quarters & 8-16 quarters & $16-32$ quarters & 8-16 quarters & 16-32 quarters \\
\hline Australia & lead & contemp. & contemp. & lead & lag & lag & lead & contemp. \\
\hline Austria & lead & contemp. & contemp. & lead & lead & lead & lead & lead \\
\hline Belgium & lead & lead & contemp. & lead & lead & lead & lead & lead \\
\hline Canada & lead & lead & contemp. & lead & lag & contemp. & lead & lead \\
\hline Switzerland & lead & lead & contemp. & lead & lead & lead & lead & lead \\
\hline Germany & lag & lag & contemp. & lag & lead & lead & lead & lead \\
\hline Denmark & lead & contemp. & contemp. & contemp. & lead & lead & lead & lead \\
\hline Spain & lead & lead & lead & lead & lead & lead & lead & lead \\
\hline Finland & lead & lead & lead & lead & lead & lead & lead & lead \\
\hline France & lead & lead & lead & lead & lead & lead & lead & lead \\
\hline United Kingdom & lead & lead & contemp. & lead & contemp. & contemp. & lead & lead \\
\hline Ireland & lead & contemp. & lead & lead & lead & lead & lead & lead \\
\hline Italy & lead & lead & contemp. & lead & lead & lead & lead & lead \\
\hline Japan & lag & lead & lead & lead & lead & lead & lead & lead \\
\hline Netherlands & lead & lag & lead & lead & lead & lead & lead & lead \\
\hline Norway & lag & lag & contemp. & lag & contemp. & lead & lead & lead \\
\hline New Zealand & lead & lead & contemp. & lead & lag & contemp. & lead & contemp. \\
\hline Lag & 18 & 18 & 0 & 12 & 18 & 6 & 0 & 0 \\
\hline Contemporaneous & 0 & 24 & 65 & 6 & 12 & 18 & 0 & 12 \\
\hline Lead & 82 & 59 & 35 & 82 & 71 & 76 & 100 & 88 \\
\hline
\end{tabular}

Source: Authors' estimates.

1/ For each pair of countries and the variable, entries in the table indicate whether the cycle in the first country leads or lags the cycle in the second country, or whether the relationship is contemporaneous, on average, over the frequency band. The numbers below indicate the percentage of countries with a given type of relation. 


\section{Appendix: Data Coverage and Sources}

The data used in the analysis covers twenty advanced countries over the period from 1981 to 2006 at quarterly frequency. The following table shows the variables used along with the data sources.

Appendix Table. List of Variables

\begin{tabular}{|c|c|c|c|}
\hline Variable & Source & Variable & Source \\
\hline Commodity industrial inputs price index & IFS & Gross domestic product & IFS \\
\hline Crude oil spot price & IFS & Gross total fixed capital formation & OECD \\
\hline Stock price index & Haver Analytics & Household real disposable income & OECD \\
\hline World demand & IFS & House price index & OECD \\
\hline World reserves & IFS & Household savings & $\mathrm{OECD}$ \\
\hline Capacity utilization & OECD & Import unit values & IFS \\
\hline Balance of payments & IFS & Imports of goods and services & IFS \\
\hline Capital stock of the business sector & OECD & Increase in stocks & OECD \\
\hline Housing stock & OECD & Industrial production & OECD \\
\hline Credit to the private sector & IFS & Labor force & OECD \\
\hline Compensation of employees & OECD & Labor force participation rate & OECD \\
\hline Compensation rate of government employees & OECD & Labor productivity of the business economy & OECD \\
\hline Compensation rate of the business sector & OECD & Labor productivity of the total economy & OECD \\
\hline Consumer price index & IFS & Long-term interest rate on corporate bonds & OECD \\
\hline Current account & OECD & Long-term interest rate on government bonds & OECD \\
\hline Current disbursements of households & OECD & Money supply, broad definition: M2 or M3 & IFS \\
\hline Current receipts of households & OECD & Money supply, narrow definition: base money, M1 or M2 & IFS \\
\hline Current transfers received by households & OECD & Other investment assets & IFS \\
\hline Dependent employment & OECD & Other investment liabilities & IFS \\
\hline Dependent employment of the business sector & OECD & Portfolio investment assets & IFS \\
\hline Foreign direct investment & OECD & Portfolio investment liabilities & IFS \\
\hline Direct investment abroad & IFS & Private final consumption expenditure & OECD \\
\hline Employment & OECD & Private non-residential fixed capital formation & OECD \\
\hline Employment of the business sector & OECD & Private residential fixed capital formation & OECD \\
\hline Exchange rate (USD per local currency) & IFS & Private total fixed capital formation & OECD \\
\hline Export unit values & IFS & Property income received by households & OECD \\
\hline Exports of goods and services & IFS & Real effective exchange rate, ULC-based & IFS \\
\hline Factor income from abroad & OECD & Self-employed & OECD \\
\hline Factor income paid abroad & OECD & Self-employment income received by households & OECD \\
\hline Financial account & IFS & Short-term interest rate & IFS \\
\hline Fixed investment in construction & OECD & Total employment & OECD \\
\hline Fixed investment in machinery and equipment & OECD & Unemployment & OECD \\
\hline Fixed investment in non-residential construction & OECD & Unemployment rate & OECD \\
\hline Fixed investment of government enterprises & OECD & Unit capital-labor costs & OECD \\
\hline Government consumption of fixed capital & OECD & Unit labor cost of the manufacturing sector & OECD \\
\hline Government current disbursements & OECD & Unit labor cost of the total economy & OECD \\
\hline Government current receipts & OECD & Unit labor costs in the business sector & OECD \\
\hline Government employment & OECD & Velocity of money & OECD \\
\hline Government fixed capital formation & OECD & Wage rate of the business sector & OECD \\
\hline Government savings (net) & OECD & Wage rate of the manufacturing sector & OECD \\
\hline Gross domestic product deflator & IFS & Wages of the government sector & OECD \\
\hline
\end{tabular}




\section{References}

Adrian, T. and H. S. Shin, 2008, "Liquidity, Monetary Policy, and Financial Cycles," Current Issues in Economics and Finance, Federal Reserve Bank of New York, 08-January.

Assenmacher-Wesche, K., and S. Gerlach, 2009, "Financial Structure and the Impact of Monetary Policy on Asset Prices," manuscript.

Belke, A. and W. Orth, 2008, “Global Excess Liquidity and House Prices,” Ruhr Economic Papers, No. 37, Ruhr-Universität Bochum.

Berger, A. and C. Bouwman, 2008, "Bank Liquidity Creation," forthcoming in Review of Financial Studies.

Bernanke, B. and M. Gertler, Mark, 1989, “Agency Costs, Net Worth, and Business Fluctuations," American Economic Review, 79(1), 14-31.

_ 1995, "Inside the Black Box: The Credit Channel of Monetary Policy Transmission," Journal of Economic Perspectives, 9(4), 27-48.

Bernanke, B., M. Gertler, and S. Gilchrist, 1999, "The Financial Accelerator in a Quantitative Business Cycle Framework," in Handbook of Macroeconomics Volume 1, ed. by J. B. Taylor and M. Woodford (New York: Elsevier).

Borio, C. and P. Lowe, 2002, “Asset Prices, Financial and Monetary Stability: Exploring the Nexus," BIS Working Paper No. 114.

Borio, C., 2006, "Monetary and Prudential Policies at a Crossroads? New Challenges in the New Century,” BIS Working Paper No. 216.

Burns, A. F. and W. C. Mitchell, 1946, Measuring Business Cycles (New York: NBER).

Brunnermeier, M. K. and C. Julliard, 2008, “Money Illusion and Housing Frenzies,” Review of Financial Studies, 21(1), 135-180.

Bry, G. and C. Boschan, 1971, Cyclical Analysis of Time Series: Selected Procedures and Computer Programs (New York: NBER).

Canova, F., 1994, Detrending and Turning Points, European Economic Review, 38, 614-623.

Chamberlain, G., 1983, "Funds, Factors, and Diversification in Arbitrage Pricing Models," Econometrica, 51, 1281-1304.

Chamberlain, G. and M. Rothschild, 1983, "Arbitrage, Factor Structure and Mean-Variance Analysis in Large Markets," Econometrica, 51, 1305-1324. 
Comin, D., and M. Gertler, 2006, "Medium-Term Business Cycles," American Economic Review, 96(3), June, 523-551.

Cooley, T. F. and E. C. Prescott, 1995, "Economic Growth and Business Cycles," in Frontiers of Business Cycle Research, ed. by T. F. Cooley and E. C. Prescott (Princeton: Princeton University Press).

Corbae, D. and S. Ouliaris, 2006, "Extracting Cycles from Nonstationary Data," in Econometric Theory and Practice: Frontiers of Analysis and Applied Research, ed. by D. Corbae, S. Durlauf, and B. Hansen (New York: Cambridge University Press).

Croux, C., M. Forni, and L. Reichlin, 2001, "A Measure of Comovement for Economic Variables, Theory and Empirics," The Review of Economics and Statistics, 83(2), 232-241.

Eickmeier, S., 2007, "Business Cycle Transmission from the U.S. to Germany-A Structural Factor Approach," European Economic Review, 51, 521-551.

Faia, E., 2007, "Financial Differences and Business Cycle Co-Movements in a Currency Area," Journal of Money, Credit and Banking, 39(1), 151-185.

Feldstein, M., 2007, "Housing, Credit Markets and the Business Cycle,” NBER Working Paper 13471.

Forni, M., D. Giannone, M. Lippi, and L. Reichlin, 2005, "Opening the Black Box: Structural Factor Models with Large Cross-Sections," manuscript.

Geweke, J., 1977, “The Dynamic Factor Analysis of Economic Time Series,” in Latent Variables in Socio-Economic Models, ed. by D.J. Aigner and A.S. Golberger (Amsterdam: North-Holland).

Giannone, D., L. Reichlin, and L. Sala, 2002, “Tracking Greenspan: Systematic and Unsystematic Monetary Policy Revised,” CEPR Working Paper 3550.

Giannone, D., M. Lenza, and L. Reichlin, 2008, "Business Cycles in the Euro Area," manuscript.

Goodhart, C. and B. Hofmann, 2008, "House Prices, Money, Credit, and the Macroeconomy," Oxford Review of Economic Policy, 24(1), 180-225.

Harvey, A. C. and A. Jaeger, 1993, "Detrending, Stylized Facts and the Business Cycle," Journal of Applied Econometrics, Vol. 8, No. 3, pp. 231-248.

Harding, D. and A. Pagan, 2002, "Dissecting the Cycle: A Methodological Investigation," Journal of Monetary Economics, 49, 365-381. 
King, R. G. and S. T. Rebelo, 1993, "Low Frequency Filtering and Real Business Cycles," Journal of Monetary Economics, 33, 405-348.

Iacoviello, M. and S. Neri, 2007, "Housing Market Spillovers: Evidence from an Estimated DSGE Model," Boston College Working Papers in Economics 659.

Imbs, J., 2004, “Trade, Finance, Specialization, and Synchronization,” Review of Economics and Statistics, 86(3), 723-734.

Kabundi, A. and F. Nadal De Simone, 2007a, "France in the Global Economy: A Structural Approximate Dynamic Factor Analysis", IMF Working Paper WP/07/129.

— , 2007b, "Recent French Export Performance: Is There a Competitiveness Problem?”, IMF Working Paper WP/08/129.

Kiyotaki, N. and J. Moore, 1997, “Credit Cycles,” Journal of Political Economy, 105(2), 211-248.

Kose, A., C. Otrok, and C. Whiteman, 2008, "Understanding the Evolution of World Business Cycles," Journal of International Economics, 75(1), 110-130.

Kose, A., E. Prasad, and M. Terrones, 2003, "How Does Globalization Affect the Synchronization of Business Cycles?" American Economic Review, 93(2), 57-62.

Kose, A. and Yi, K. M., 2006, "Can the Standard International Business Cycle Model Explain the Relation between Trade and Comovement?" Journal of International Economics, 68(2), 267-295.

Kwiatkowski, D., P. Phillips, P. Schmidt, and Y. Shin, 1992, "Testing the Null Hypothesis of Stationarity Against the Alternative of a Unit Root: How Sure Are We That Economic Time Series Have a Unit Root?” Journal of Econometrics, 54, 159-178.

Leamer, E., 2007, “Housing is the Business Cycle,” NBER Working Paper 13428.

Meier, A. and G. Müller, 2006, "Fleshing out the Monetary Transmission Mechanism: Output Composition and the Role of Financial Frictions," Journal of Money, Credit and Banking, 38 (8), 14-30.

Mishkin, F., 2007, "Housing and the Monetary Transmission Mechanism," Proceedings, Federal Reserve Bank of Kansas City, 359-413.

Otrok, C. and M. Terrones, 2005, "House Prices, Interest Rates, and Macroeconomic Fluctuations: International Evidence," manuscript.

Sargent, T. J., and C. A. Sims, 1977, "Business Cycle Modeling without Pretending to have too Much a Priori Economic Theory," in New Methods in Business Research, ed. by C.A. Sims (Minneapolis: Federal Reserve Bank of Minneapolis). 
Stock, J.H., and M.W. Watson, 1998, “Diffusion Indexes,” NBER Working Paper 6702. 1999, "Business Cycle Fluctuations in U.S. Macroeconomic Time Series," Handbook of Macroeconomics, Volume 1, Edited by J.B. Taylor and M. Woodford. 